\title{
Research on the Problems and Countermeasures in the Process of College Students' Physical Fitness Test
}

\author{
Hao Xiong \\ Hubei Business College \\ Wuhan, China 430079
}

\begin{abstract}
In September, 2007, the Ministry of Education and the General Administration of Physical Education jointly promulgated the Student Physical Health Standard, which quantifies the standard of students' physical health, reflecting the degree of emphasis of the Ministry of Education and the General Administration of Physical Education on students' physical health. From the $\mathbf{1 0}$ years from the promulgation of "Student Physical Health Standard" to its implementation, the problems in the implementation of "Student Physical Health Standard" are gradually reflected. Through participation in the work of college students' physical fitness test for many years, it is found that the physical fitness test of college students can not truly reflect and evaluate the problems of college students' physical fitness. This paper analyzes and studies the problems in the process of test from the tester, the testee and the testing instrument, and puts forward some suggestions to solve the practical problems, in order to promote the results of college students' physical fitness test to develop in a better direction.
\end{abstract}

Keywords-college students; physical fitness test; existing problems; solutions

\section{INTRODUCTION}

Student Physical Health Standard jointly organized by the Ministry of Education and General Administration of Sport has been officially implemented for twelve years. During the period, a major reform was carried out. In 2012, a clear requirement was put forward for the test, the test items were adjusted, and each university student was required to take a physique test, of which the test results were linked to the evaluation, and the students who graduate with a test score of less than 50 points are considered school noncompletion. Student Physical Health Standard is an educational means to urge students to develop their physique healthily and encourage them to exercise actively. It is also an individual evaluation standard of students' physique health. The physical fitness test of college students is a test item to know the physical fitness of students based on this premise. It is scientific, inspiring, guiding and supervising, which can not only urge students to exercise, but also grasp the physical fitness of students, and it is very necessary to supervise the physical education teaching better. However, there are always some problems in the physical fitness testing of colleges and universities influencing the result of the test and the realization of the purpose of the test. This paper investigates the problems existing in the test of college students' physique, puts forward the feasible countermeasures, and analyzes the solutions to them, so as to promote the result of physical test of university students to develop in a better direction.

\section{The EXISTING PROBlems IN COLLEGE StUdents' PHYSIQUE FITNESS TEST}

\section{A. Inadequate Manpower and Material Input and Low Motivation of Testers}

Due to the heavy workload of physical education teachers, particularly in the private colleges and universities where average weekly hours of most physical education teachers are 20 classes, during the process of tests in September, October and November, the average weekly hours of each teacher are nearly 30 . Not only should they complete the tests for freshmen and sophomore in the classroom, but also they should arrange the contents of the tests for junior and senior students after class. Even at weekends, the test will be arranged from 8 a.m. to 5 p.m. A great deal of testing work makes testers feel bored, so the lack of human and material resources prevents testers from being motivated, leading to less serious testing. Therefore, there will be many factors affecting the authenticity of the test, which are mainly reflected in the following aspects.

1) Testing processes and methods are not scientific and reasonable: The implementation of health testing does not clearly specify the sequence of test items. How to arrange test items is decided by P.E. teachers according to the situation. And most schools are facing the situation with large number of students, less instrument, few testing teachers, limited site and urgent testing time. In order to complete the health test work as soon as possible, many teachers have not considered the scientific and reasonable test flow to merely pursuit speed. For example, students run 800 meters immediately after running 50 meters, and do standing long jump or pull up immediately after doing situps, which will greatly affect the accuracy and reasonableness of the data. In addition, the preparatory activities before the physical fitness test are also very important and necessary, so the adequacy of the preparatory activities will also affect the physical fitness test data.

2) Teachers' attitude towards testing is not serious enough: In the work of physical fitness test, physical 
education teachers are working in the front line. It is very important for teachers to organize students' tests and to prevent cheating. The workload of test teachers is very heavy because of the large number of test people, the short time and the small number of test teachers, which leads to the rigorous and oversimplified test process. For example, a group of 10 people or even more do sit-ups at the same time, and the students count each other. Many report false data. As for 800 meters or 1000 meters, students of one class run in two groups, and the phenomenon of foul of students in running is serious; The movement of sit-and-reach and pullups are not standard and the criterion is not easy to grasp, which influence the authenticity of the test results to a great extent. Junior and senior students no longer have physical education classes, so test teachers are not familiar with students, and the test scene cannot be controlled. It is difficult to check each student's credentials, and the phenomenon of substitution is serious. Such problems can directly affect the accuracy and authenticity of the data.

\section{B. Undergraduates' Inadequate Attention to Health Testing}

Students do not pay attention to the test before, and do not care the results after the test. They don't have crisis awareness on their own physique. Since publicity is not in place, most students do not really realize the true purpose and significance of the test, let alone the function and role of the test. Through investigation, many college students pay inadequate attention to the physical test process and results. They generally believe that the results of the test do not have a great impact on their academic results. It is nothing more than a supplementary test, which will not affect graduation and school performance. Therefore, most students will not play their real level, but treat the physical test with a coping attitude, let alone the targeted exercise in daily life. The lack of appropriate incentive mechanism leads to the lack of students' motivation to participate in physique tests. Many colleges and universities do this to cope with the basic regulations of the country, without spending energy on the students' physique test work. It is because the university does not care that students' physique level is not high and the significance of carrying out the physique test is lost. Therefore, the physical fitness test work also has no vigor and motivation.

\section{The Quality Problems of Instrument Result in Inaccurate Data}

Due to the long durable years of test instrument in many colleges and universities, there are problems such as aging, backwardness and damage, which lead to frequent problems in the process of testing. For example, in the height and weight test, the data of height of many students is lower than that of the previous year, and the accuracy of weight is not high, or even be out of order; in the use of spirometer, the instrument was not disinfected in time, and the induction of the sensors of vital capacity is not sensitive, impacting the vital capacity data. In addition, in the using of many instruments, there is a certain damage phenomenon, but it cannot be timely maintained and replaced, resulting in the impact of the accuracy of the data. The problems of the instrument increase the difficulty of the test, but the school failed to take effective measures to solve them, and the test teachers did not pay attention to it, causing the problem to aggravate ceaselessly.

\section{The Data Processing after Testing Lacks Normalization}

After the students' physical fitness test, the test teacher mainly collates, arranges, counts and reports the data. Because there are tens of thousands of people taking part in the test in each university, it is unavoidable that some students miss some test items in the test process and the school will arrange the supplementary test, but still many students do not take part in the supplementary test. In order to complete the task, the test teacher directly filled in the students' scores at random, showing an extremely irresponsible attitude. In the process of data reporting, there is also such a phenomenon. After the scoring of whole school students' physical test data, it is found that the pass rate is very low, which cannot reach the evaluation standard required by the Department of Education. Therefore, many schools adjust students' physical test scores privately to form a kind of bad result of fraudulent practice in order to achieve the "standard".

\section{STUdy ON THE COUNTERMEASURES TO THE PROBLEMS IN THE PROCESS OF TESTING}

\section{A. Schools Attach Great Importance to Strengthening the Dissemination and Implementation of the Purpose and Significance of the Standards}

Before carrying out the students' physical fitness test, the school should organize various departments to hold the coordination meeting of physical fitness test, strengthen the publicity and the degree of emphasis to the "student's physical fitness test standard", to make every student realize the purpose and the significance of participating in the physical fitness test profoundly, change the negative psychological consciousness thoroughly, treat each test seriously, and bring into play their true level. At the same time, it is necessary to increase the investment, do well the training of test teachers, so that test teachers can really master the test methods of each test item. They should strictly require teacher, put forward the corresponding reward and punishment system, improve the extra work remuneration of test teachers, stimulate teachers' enthusiasm for work, and enhance teachers' sense of responsibility, to ensure the authenticity of data from test to statistical report.

\section{B. Arranging the Time and Sequence of Physical Fitness Tests Scientifically and Reasonably}

Reasonable arrangement of test time and the sequence of test items are of great significance to improve the accuracy of physical fitness testing. Schools should properly arrange the test projects, develop a sound test plan, reasonably allocate students' physical fitness, and all the projects should be arranged at least two tests. For example, they can place 1000 meters for boys and 800 meters for girls that consumes much strength in the end of the test, while simple items such 
as height and weight, vital capacity and sit-and-reach can be put in front of the test. After doing sit-ups, they can run 50 meters, and do standing long jump after doing pull-ups. In this way, the test items are reasonably arranged, making the arrangement of project process more scientific and reasonable.

\section{Timely Inspection and Replacement of Test Instruments}

Due to the long-term high-density testing, sensitivity and reliability of test instrument will be declined, so every year before the physical fitness testing, the instrument should be inspected in advance by specially-assigned person and it should be replaced in time for damage or lack of sensitivity and so on. For all colleges and universities, physical fitness testing is a tedious and burdensome task. All students in the school need to take physical fitness tests every year, and the instrument for one test item will be reused for tens of thousands of times. In order to avoid decreasing the accuracy of test instruments and shortening the service life, it is recommended that regular maintenance be carried out. According to the specific situation of the school, a few more instruments can be equipped with, so that the efficiency of the test can be greatly improved.

\section{Establishing a Long-term Mechanism to Improve Test Management and Supervision}

From the beginning of college entrance, the school test center establishes the health file for each college student's physical fitness test. After the test of each school year, the result is put into file in the form of written report, and exercise suggestion is put forward to those who do not meet the test target, and the qualification certificate is issued to those who meet the test target. The result is linked with the evaluation of the outstanding students and recommendation to joining the party in each school year. The four-year comprehensive test results can be used as one of the conditions for successful graduation. Through linking the test and physical education results, we can promote the enthusiasm of students to participate in sports activities and gradually develop the consciousness of self-active exercise. Linking the test with the students' actual interests can arouse the students' real attention. Especially for the junior and senior students who have no physical education examination, we can use the physical fitness test to measure the result of the "physical fitness" in the "three good."

\section{CONCLUSION}

The university physical fitness test uses certain methods and means with the aid of related instruments to test the students' physical health situation. The purpose of the test is to obtain the data of students' physical fitness and analyze the data so as to grasp the students' health situation in an allround way. How to improve the accuracy of student health test data is the problem that each of our school leaders and teachers should think about. If we only want to cope with the national regulations to carry out physical fitness testing, it is irresponsible for students as educators. We should continue to explore and take effective measures to address the problem, to eliminate unnecessary shortcomings and mistakes as far as possible, and better promote the development of physical fitness testing for college students.

\section{REFERENCES}

[1] Zhang Chunlei. Research on the Present Situation of College Students' Physical Fitness Test [J]. Jilin Normal University Journal Natural Science Edition. 2012.11 (4): 23-24. 张春雷.关于普通高校 大学生体质测试现状的研究 [J]. 吉林师范大学学报: 自然科学 版.2012.11 (4) :23-24.

[2] Liu Jianjin. Study on Influencing Factors and Countermeasures of College Students' Physical Test [J]. Journal of Chifeng University. 2015 (3). 刘建进.大学生体质测试的影响因素及对策探讨 [J].赤峰 学院学报.2015 (3).

[3] Yang Chuanchuan. Influencing Factors and Development Strategies of College Students' Physical Fitness Test [J]. Contemporary Sports Technology, 2014, 14: 71-72. 杨川川.大学生体质测试影响因素与 发展对策[J].当代体育科技，2014，14：71-72。

[4] Yang Jian, Yang Haizhou. Research on the Problems and Countermeasures of College Students' Physical fitness Test [J]. Journal of Xianning University, 2019, (6). 阳剑, 杨海洲.普通高校 大学生体质测试存在的问题及对策研究 [J]. 咸宁学院学报, 2019, (6). 